\title{
INVESTIGATIONS OF NEUTRAL RADICAL MOLECULES SUITABLE FOR QUANTUM INFORMATION PROCESSING
}

\author{
J. Tamuliené ${ }^{\mathrm{a}}$, Ž. Rinkevičius ${ }^{\mathrm{b}}$, and A. Tamulis ${ }^{\mathrm{a}}$ \\ ${ }^{a}$ Institute of Theoretical Physics and Astronomy of Vilnius University, A. Goštauto 12, LT-01108 Vilnius, Lithuania \\ E-mail: gicevic@itpa.1t \\ ${ }^{\mathrm{b}}$ Royal Institute of Technology, SCFAB, SE-10691 Stockholm, Sweden
}

Received 2 May 2007; revised 28 May 2007

\begin{abstract}
Neutral radical molecules as qubit systems for quantum information processing are described and the application of quantum chemistry methods in search of suitable radicals is outlined. An exemplifying calculation of the relevant magnetic properties of neutral radicals is presented and the suitability of these compounds as building blocks for a quantum computing device based on self-assembled monolayer of radicals is assessed.
\end{abstract}

Keywords: qubits, quantum computing device, neutral radical, $g$-tensor

PACS: $31.15 . \mathrm{Ar}$

\section{Introduction}

Quantum computation and quantum information principles are developed to accomplish the information processing task using quantum mechanical systems. The main challenge on the way to a universal quantum computer is to achieve control over a single quantum mechanical two-state system while preserving long decoherence times [1]. Electron and nuclear spins have been identified as promising candidates for qubits because they are natural two-state systems and the decoherence times for the spin degree of freedom are unusually large. The molecules with their widely varying properties offer a bright interesting field for the investigations concerning elements of quantum computation $[2,3]$. Among the other systems proposed so far, the molecular nanodevices should be one of the most promising candidates, because of the possibility to isolate them from the environment and their good controllability with the well-established technique of electron spin resonance (ESR). Scientists at MIT and Los Alamos National Laboratory created a seven-qubit quantum computer within a single drop of liquid $[4,5]$. In [6] Bandyopadhyay reviews the use of single electron spins for computation and provides a broad perspective pertaining to the use of single electron spins for logic.

Synthesis and investigations of novel stable organic radicals are important for the development of spin chemistry underlying molecular-based magnetic materials [7]. Hyperfine splittings were obtained due to protons of radicals by solution ESR / ENDOR (electron nuclear double resonance), and they indicated unpaired electron delocalization. Thus, the radicals seem to be good candidates to generate qubits because the four requirements for quantum computation are in many cases satisfied: (i) representation of quantum information; (ii) performance of a universal family of unitary transformations; (iii) preparation of fiducial initial states; (iv) measurement of output results. Recently, it has been shown that self-assembled monolayer (SAM) molecular system with unpaired spin can be used in quantum logic devices [8]. There it has been shown that a sequence of three resonant pulses can drive the SAM molecular system into an entangled state and these states are measured using the oscillating cantilever driven adiabatic reversal (OSCAR) technique. It is emphasized that the magnetic field gradient allows one to selectively excite any spin in a group. Roughly speaking the SAM molecular system consisting of neutral radicals is an important step towards the application of long chains of electron spins in quantum computation and quantum information processing.

The above-mentioned proper sequence of resonance electromagnetic pulses would drive all spin groups into the 3-spin entangled state. However, the long spin relaxation times are important for the success of many proposed quantum computing and spintronic devices, 
as well as for manipulation and imaging of individual spins [9]. Moreover, the spin relaxation and related quantum decoherence effects may be strongly influenced by the local electronic environment. So, the proper choice of molecules for the experimental implementation is a key element of this strategy. Hence, the aim of our work is to show the investigated radicals as good candidates to be used in quantum computations.

The novel OSCAR technique as a tool for read-out of the spin states has been recently implemented successfully for the single-spin detection [10]. The process of spin relaxation in the oscillating cantilever-driven adiabatic reversal technique in a magnetic-resonance force microscopy is described by Berman et al. [11]. The technique is suitable for characterizing the spin behaviour with high sensitivity and nanometre-scale spatial resolution. On the other hand, it was exhibited that the self-assembling monolayer (SAM) systems could be used to create a macroscopic ensemble of quantum entangled spin groups, as a first step towards the parallel quantum information processing. The unpaired electron spin of each radical (radicals are in doublet ground state $S=1 / 2$ ) acts as qubit in a spin group and the gradient of static external magnetic field is applied to spatially ordered SAM of radicals in order to separate the energy levels of qubits via Zeeman effect. In such a system, the nonlinear interaction between qubits, required for achieving entanglement in a spin group, is provided by a classical dipole-dipole interaction between the spins of radicals or alternatively by exchange interaction. There are several criteria for the chemical structure of these molecules involved in this choice: (i) an unpaired electronic spin representing an elementary qubit; (ii) a specific group to provide an attachment of the molecule to a substrate in SAM; (iii) a specific group or structural elements to provide selforganization characteristics; (iv) a large separation of an energy level of qubit via Zeeman effect to lower the decoherence; (v) an entanglement in spin group.

Hence, in this paper we exhibit that our suggested radicals satisfy the above-mentioned criteria and consequently could be applied in quantum computing.

\section{Computational methodology}

The quantum chemical $a b$ initio density functional theory (DFT) investigations were applied with the Berny geometry optimization to gain chemical structure information on an isolated molecule $[12,13]$. Currently, the UB3LYP model is considered to be the
Table 1. Formation energy per atom of investigated radicals.

\begin{tabular}{cc}
\hline Radical & Formation energy per atom, eV \\
\hline$I$ & 5.68 \\
II & 5.27 \\
III & 4.81 \\
\hline
\end{tabular}

most appropriate model to take into consideration electron correlations in a large open-shell neutral radical molecule. To obtain the accurate optimal molecular geometries, we use the $6-311 \mathrm{G}^{* *}$ basis set which includes $(5 \mathrm{D}, 7 \mathrm{~F})$ polarization functions [14]. To analyse the spatial electronic spin localization and stability at a relaxed molecule geometry, we subsequently use the extended EPR-II basis set. The EPR-II basis set includes the re-optimized Huzinaga-Dunning double-zeta $[15,16]$ basis sets augmented with the additional polarization functions and the uncontracted in outer core-inner valence region. The investigation results applying this basis set in conjunction with the B3LYP functional have been shown to closely reproduce the experimental splittings of ${ }^{1} \mathrm{H},{ }^{13} \mathrm{C}$, and ${ }^{14} \mathrm{~N}$ in a number of small- and medium-sized radicals, although for hydrogen in some cases there is no gain in accuracy over a smaller 6-31G* basis set of Pople $[17,18]$. The radical electron $g$-factor is investigated applying the approach presented in [19]. Additionally, the results of the isotropic hyperfine coupling constant using the restricted-unrestricted (R-U) approach at the DFT level are also presented. In this case the BP86 functional with Huz-II basis with uncontracted $s$-functions and the additional two tight $s$-functions set is applied.

\section{Analysis of electronic structure in neutral radical molecules}

The views of shortened neutral radical molecules are presented in Figs. 1-3. We mark these radicals $I, I I$, and III. The original names of these radicals are the following: $I$ is 7-butyl-1-oxa-6-oxo-1,2,5,6 tetra hydroantracene-2-carboxyl; II is 5-methyl-6-(4-oxo2,5-cyclohexodienyl)hexane, and III is 6-ethyloctane.

It is emphasized that all these radicals are stable enough, this is indicated by an evaluated value of formation energy per atom (see Table 1). Firstly, it is necessary to point out that all our investigated radicals contain a hydrophobic tail that can be used for the self-assembled monolayer formation [20]. These tails are substituted by a - $\mathrm{COOH}$ group that can provide the necessary attachment to the substrate for cases 


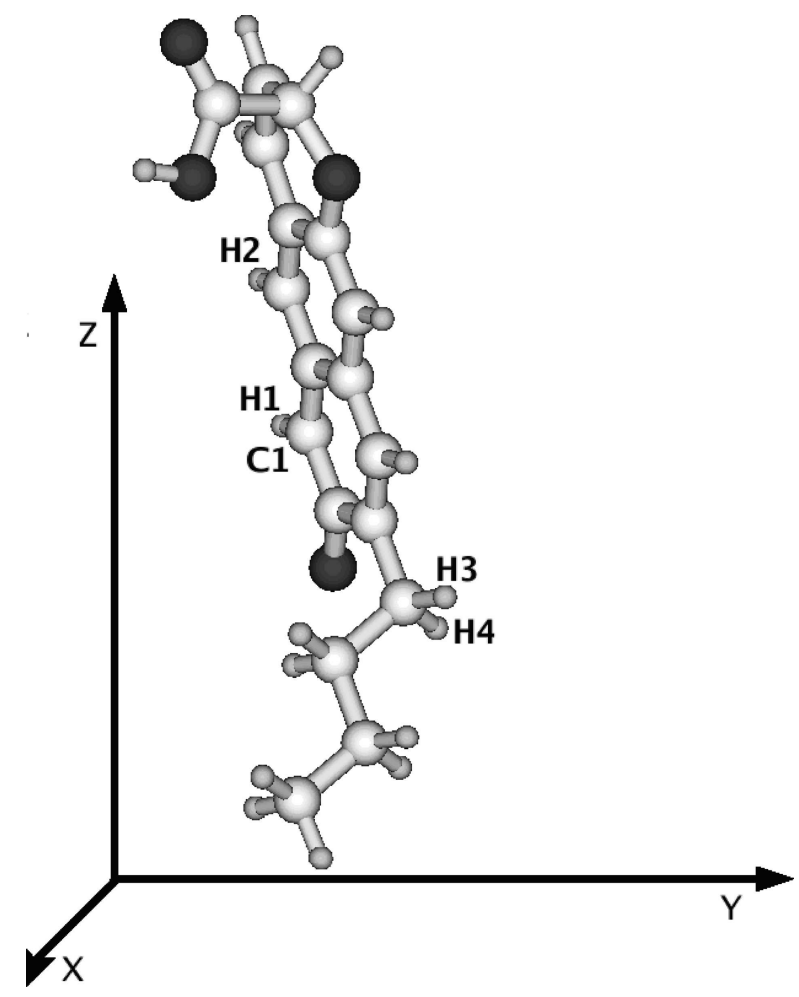

Fig. 1. View of investigated radical $I$. The axes show $g$-factor component directions.

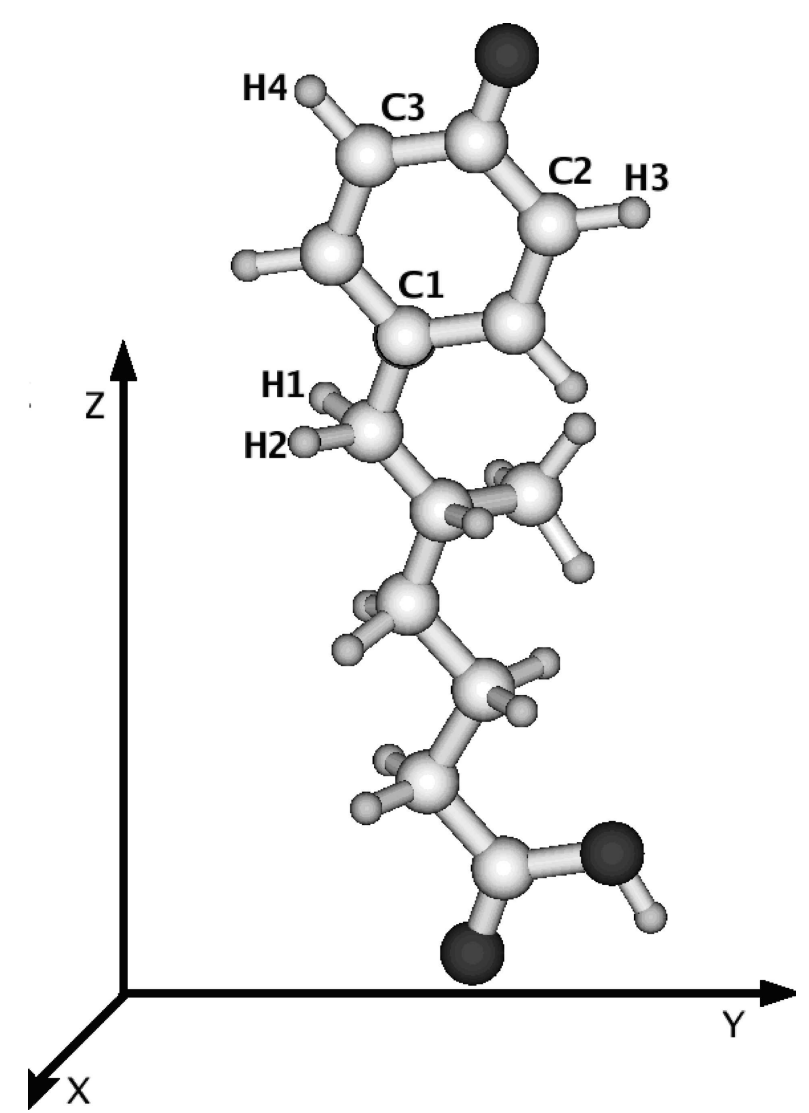

Fig. 2. View of investigated radical $I I$. The axes show $g$-factor component directions.

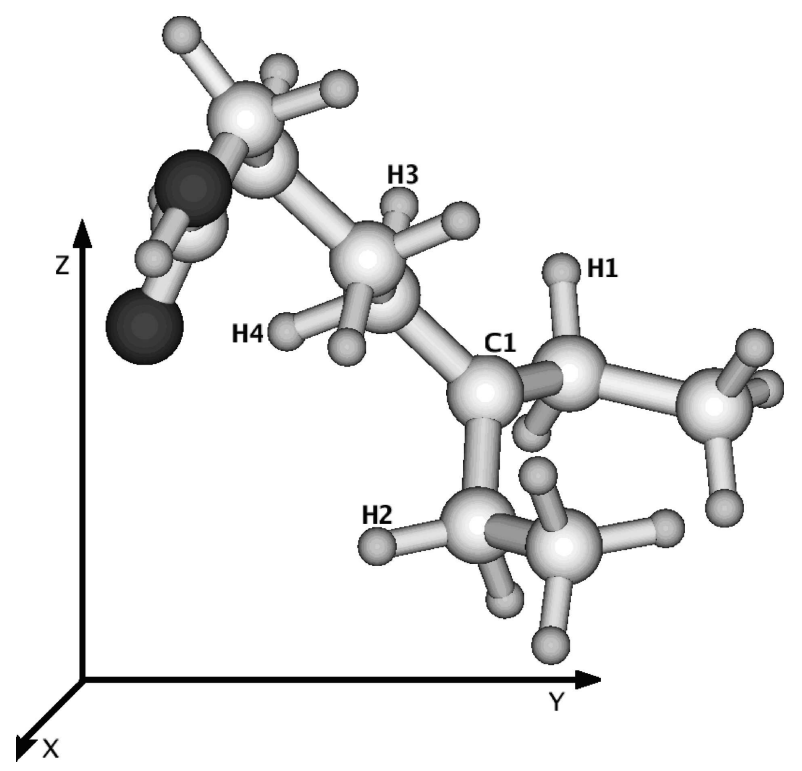

Fig. 3. View of investigated radical III. The axes show $g$-factor component directions.

Table 2. The largest spin density values obtained in the investigated radicals. The placement of atom is viewed in Figs. 1-3.

\begin{tabular}{cccc}
\hline Atoms & I radical & II radical & III radical \\
\hline C1 & 0.45 & 0.4 & 0.97 \\
C2 & & 0.31 & \\
C3 & & 0.29 & \\
O & 0.34 & 0.41 & \\
\hline
\end{tabular}

of a variety of inorganic oxide materials such as aluminium oxide $[21,22]$. So, all these radicals possess the structural elements to provide self-organization and the attachment of these molecules to a substrate SAM. It was noted that the research of slightly modified radicals (the tail was substituted by a $-\mathrm{CH}_{3}$ group) was made to foresee how the substitute influenced the electronic structure of these radicals. It was concluded that the electronic structure of these radicals was independent of substitution of their tails as well as tail lengths [23].

It is no surprise that in the $I$ and $I I$ radicals the unpaired electron is thought to reside primarily in the $\pi$-orbitals of the aromatic rings, which have no spin density in the plane of the molecule where the hydrogen nucleus resides [24]. The suggested III radical structure is completely different from that of other radicals under investigation, thus in this case the unpaired electron is delocalized on $\mathrm{C}-\mathrm{C}$ bonds. However, the spin density distribution in this molecule is very promising (see Table 2). In this case the highest spin density localization is clearly known. 
Table 3. Isotropic Fermi contact coupling constants obtained applying B3LYP EPR-II approach. The placement of atom is viewed in Figs. 1-3.

\begin{tabular}{cccc}
\hline Atom & I radical & II radical & III radical \\
\hline H1 & -22.58 & 71.9 & 106.47 \\
H2 & -8.03 & 70.39 & 108.88 \\
H3 & & -17.94 & 30.26 \\
H4 & & -14.15 & 28.33 \\
\hline
\end{tabular}

Table 4. $g$-factor and its $g$-shift tensor components of the investigated radicals.

\begin{tabular}{cccc}
\hline Molecule & $g_{x x}, \mathrm{MHz}$ & $g_{y y}, \mathrm{MHz}$ & $g_{z z}, \mathrm{MHz}$ \\
\hline$I$ & 100 & 2563 & 7040 \\
II & 2837 & 189 & 10450 \\
III & 40 & 495 & 404 \\
\hline
\end{tabular}

In Table 3, we decompose the obtained isotropic Fermi contact coupling constants. It is evident that well-defined EPR spectra lines will be obtained in the spectra of these radicals. Actually it is a surprise that the isotropic Fermi contact coupling values are very large, therefore the parameters have been reinvestigated applying the restricted Kohn-Sham formalism for the first order properties using the R-U approach that is implemented in DALTON. The results obtained by using the above-mentioned approaches coincide well.

In order to obtain some more results to confirm the above molecules as promising candidates for quantum computation, the electronic $g$-tensor, which accounts for the influence of the local electronic environment in the molecules on the unpaired electrons compared to the free electron, has also been investigated. In the simplest case of a free electron, the $g$-factor has the value $g_{\mathrm{f}}=2.00232$. In all interesting chemical applications, the electron is in an atomic or molecular orbital and its magnetic moment has contributions both from the orbital and the spin degrees of freedom. The $g$-factor deviates from the free electron value in a way that is characteristic of its environment. In addition, the $g$-value depends on the orientation of the magnetic fields with respect to the local environment of the unpaired electron. When both a molecule and created field $g$-tensors are known, it is possible to choose the angle between the above $g$-tensors in such a way that the spin-dipole interaction is absent. Thus, the decoherence is lowered. The electronic $g$-shift tensor components of the chosen molecules are presented in Tables 4,5. The $g$-factor values correspond to the one of free electron in the case of the III radical. It implies that indeed the free electrons in this radical are present and it is possi-
Table 5. The $g$-factor components.

\begin{tabular}{cccc}
\hline Molecule & $g_{x}$ & $g_{y}$ & $g_{z}$ \\
\hline$I$ & 2.0024 & 2.00488 & 2.0094 \\
II & 2.0025 & 2.005 & 2.0127 \\
III & 2.0024 & 2.0028 & 2.0027 \\
\hline
\end{tabular}

ble to foresee that the orientation of the magnetic field with respect to the local environment of the unpaired electron is not needed. It simplifies the application of electron spin as a qubit.

So, the $I$ and $I I$ radicals under investigation have a high electronic $g$-tensor with large $g_{z z}$ component that lies in the plane of these radicals. The placement of the above component is suitable for EPR quantum computing when the magnetic field plays an important role. In both these cases the $g_{y y}$ component goes out of these molecules planes, and quantum computation with spin qubit without any difficulty could be performed. The $g_{x x}$ component lies in the tail of $I$ and $I I$ radicals, however, only in the case of II radical the above component is the smallest. Such orientation of the $g$-tensor components allows us to foresee that the difficulties significant for the quantum computation prospectives, namely, obtaining well-defined frequencies of the transitions, should be absent in the case of II radical, because a fixed orientation of the electronic $g$-tensor principal axes with respect to the external magnetic field will take place. On the basis of these results it is possible to predict that the $I I$ radical molecule is a promising candidate for the quantum logical device when OSCAR technique is used.

The large value of $g_{x x}$ component in the tail of the $I$ radical molecule is not suitable for the OSCAR technique. Though the radical could also be used as a quantum logical device, in this case it is necessary to use another technique, where the above $g$-tensor component value is not important.

Attention should be paid to III radicals. All results indicate that in this radical a free electron is present. The $g$-tensor component values correspond to those of the free electron and $g$-tensor shift value components are small. It implies that the $I I I$ radical molecule is a promising candidate for a quantum logical device.

The optical spectra of these radicals were investigated to see the separation of energy levels of a qubit via Zeeman effect to lower the decoherence. We presented here only the spectral lines representing the splitting due to the Zeeman effect (Table 6). It helps to verify the entagled state of the two-spin system due to dipole-dipole interaction between the spins. 
Table 6. Lines in spectra of the investigated radical representing the separation of energy due to the Zeeman effect.

\begin{tabular}{ccc}
\hline$I$ radical & II radical & III radical \\
\hline $929.31 \mathrm{~nm}$ & $1077.78 \mathrm{~nm}$ & $1013.26 \mathrm{~nm}$ \\
\hline
\end{tabular}

\section{Conclusions}

Using the quantum chemical methods based on the density functional theory we have studied the several neutral radical molecules that may serve as prototypes for designing molecules to be used in the experimental targeting quantum computation with the SAM structures and the OSCAR technique.

Our analysis of the spatial localization of the electron spin density shows that the neutral radicals satisfy the requirements formulated in our work. It implies that the specific group to provide an attachment of the molecule to a substrate SAM is present and the selfassembled monolayer formation should take place. The elementary qubit has been represented by the unpaired electron spatially localized on certain atoms.

The fixed orientation of the electronic $g$-tensor principal axes with respect to the external magnetic field supports the absence of significant difficulties for the quantum computation prospectives in the case of the $I I$ and III radicals. In the case of $I$ radical only one criterion of the $g$-tensor component is unsatisfied: the $g$-shift component that lies in the tail of the radical is too large. Due to the above-mentioned reason the $I$ radical is not suitable for the quantum computation with OSCAR technique.

On the other hand, the attention should be paid to III radicals. All obtained results indicate that there is a free electron in this radical. The $g$-tensor component values correspond to those of the free electron and the $g$-tensor shift value components are small. Hence the III radical molecule is a very good candidate to be used in quantum computation.

\section{Acknowledgements}

This work is supported by the NorFA funded grant "Quantum Modelling of Molecular Materials" and partly by the Lithuanian State Science and Studies Foundation. We are grateful to Prof. A. Graja and Poznan's Supercomputing and Networking Center for the possibility to use CRAY and Gaussian98 package, as well as Computing Centre of Vilnius Gediminas Technical University for the possibility to use their cluster and GAMESS package. J. Tamulienè thanks Dr P. Norman for discussions and hospitality at the Linköping University, Dept. of Physics, Linköping, Sweden.

\section{References}

[1] L.M.K. Vandersypen, Experimental Quantum Computation with Nuclear Spins in Liquid Solution, dissertation submitted to the Department of Electrical Engineering and the Committee on Graduate Studies of Stanford University (2001).

[2] R. Marx, A.F. Fahmy, J.M. Myers, W. Bermel, and S.J. Glaser, Phys. Rev. A 62, 012310-1 (2000).

[3] Published by the MIT News Office at the Massachusetts Institute of Technology, Cambridge, Mass., March 29, 2000.

[4] E. Knill, R. Laflamme, R. Martinez, and C.-H. Tseng, Nature 404, 368 (2000).

[5] Y. Morita, J. Kawai, S. Nishida, K. Fukui, S. Nakazawa, K. Sato, D. Shiomi, T. Takui, and K. Nakasuji, Polyhedron 22, 2205 (2003).

[6] S. Bandyopadhyay, Superlatt. Microstruct. 37, 77 (2005).

[7] C.W. Hollars, S.M. Lane, and T. Huser, Chem. Phys. Lett. 370, 393 (2003).

[8] G.P. Berman, V.I. Tsifrinovich, and D.L. Allara, Phys. Rev. B 66, 193406-1 (2002).

[9] B.C. Stipe, H.J. Mamin, C.S. Yannoni, T.D. Stowe, T.W. Kenny, and D. Rugar, Phys. Rev. Lett. 87, 277602-1 ( 2001).

[10] D. Rugar, R. Budakian, H.J. Mamin, and B.W. Chui, Nature 430, 329 (2004).

[11] G.P. Berman, V.N. Gorshkov, D. Rugar, and V.I. Tsifrinovich, Phys. Rev. B 68, 094402-1 (2003).

[12] Extensible Computational Chemistry Environment Basis Set Database, Environmental and Molecular Sciences Laboratory at Pacific Northwest Laboratory, P.O. Box 999, Richland, Washington 99352, USA.

[13] S. Huzinaga, J. Chem. Phys 42, 1293 (1965).

[14] G.A. Petersson, A. Bennett, T.G. Tensfeldt, M.A. AlLaham, W.A. Shirley, and J. Mantzaris, J. Chem. Phys. 89, 2193 (1988).

[15] V. Barone, in: Recent Advances in Density Functional Methods, Part I, ed. D.P. Chong (World Scientific, Singapore, 1996).

[16] G.A. Petersson and M.A. Al-Laham, J. Chem. Phys. 94, 6081 (1991).

[17] V.A. Rassolov, M.A. Ratner, J.A. Pople, P.C. Redfern, and L.A. Curtiss, J. Comp. Chem. 22, 976 (2001).

[18] V.A. Rassolov, J.A. Pople, M.A. Ratner, and T.L. Windus, J. Chem. Phys. 109, 1223 (1998).

[19] Z. Rinkevicius, L. Telyatnyk, O. Vahtras, and H. Agren, J. Chem. Phys. 121, 7614 (2004)

[20] G.P. Berman, F. Borgonovi, Z. Rinkevicius, and V.I. Tsifrinovich, Superlatt. Microstruct. 34, 509 (2003). 
[21] G. Fletcher, S. Mason, J. Terrett, and M. Soloviev, J. Nanobiotechnol. 1:1 (2003).

[22] J.A.J. Fitzpatrick, F.R. Manby, and C.M. Western, J. Chem. Phys. 122, 084312-1 (2005).
[23] V. Balzani, Photochem. Photobiol. Sci. 2, 45 (2003).

[24] Ch. Li, W. Fan, B. Lei, D. Zhang, S. Han, T. Tang, X. Liu, Z. Liu, S. Asano, M. Meyyappan, J. Han, and Ch. Zhou, Appl. Phys. Lett. 84, 1949 (2004).

\title{
NEUTRALIU RADIKALŲ, TINKAMU KVANTINEI INFORMACIJAI APDOROTI, TYRIMAI
}

\author{
J. Tamulienė ${ }^{\mathrm{a}}$, Ž. Rinkevičius ${ }^{\mathrm{b}}$, A. Tamulis ${ }^{\text {a }}$ \\ ${ }^{a}$ Vilniaus universiteto Teorines fizikos ir astronomijos institutas, Vilnius, Lietuva \\ ${ }^{\mathrm{b}}$ Karališkasis technologijos institutas, Stokholmas, Švedija
}

\section{Santrauka}

Tankio funkcionalo metodu (UB3LYP) 6-311G** bazès artinyje tirti neutralūs radikalai. Išaiškinta, kad ne visi iš ju galètų būti panaudoti elektronų paramagnetinio rezonanso (EPR) kvantiniuose kompiuteriuose, kuriuose yra naudojami savisusirenkantys neutraliu radikalu sluoksniai. Rezultatai rodo, kad tik 5-metil-6-(4-okso-2,5-cikloheksadienil)heksano rūgštis (darbe pažymèta $I I)$ ir 6-etiloktano rūgštis $(I I I)$ gali būti naudojamos kvan- tinei informacijai apdoroti. Aukščiau minètam informacijos apdorojimo būdui 7-butil-1-oksa-6-okso-1,2,5,6 tetra hidroantracen-2karboksil rūgšties (I) radikalas netinka, nes elektrono sukinio orientacija yra tokia, kad ji bus sunku valdyti bei ji stipriai veiks aplinka.

Remiantis gautais $g$ tenzoriaus tyrimo rezultatais galima teigti, kad tik III radikale yra laisvas elektronas, kurio lokalizacijos vieta yra nustatyta, todèl šis neutralus radikalas yra tinkamiausias kvantinei informacijai apdoroti. 